\title{
CORRIGENDUM
}

\section{Asclla regulates Müller glia dedifferentiation and retinal regeneration through a Lin-28-dependent, let-7 microRNA signalling pathway}

\section{Rajesh Ramachandran, Blake V. Fausett and Daniel Goldman}

Nat. Cell Biol. 12, 1101-1107 (2010); published online 10 October 2010; corrected after print 25 February 2015

In the version of this Letter originally published the first lin-28 targeting morpholino oligonucleotide should have read: 5'-GGGCATCTTTATG ATTTAGCCTTCT-3'. This has been corrected in all online versions of the Letter. 